\title{
Convergence of Financial Politics and Regulation on the Financial Markets to the Stimulation of the Economy
}

\author{
Abramkin S. A. ${ }^{1}$, Hayaleeva C. S. ${ }^{1}$, Bagautdinova N. G. ${ }^{2} \&$ Karpova N. V. ${ }^{3}$ \\ ${ }^{1}$ Kazan State Agrarian University, 65 K.Marx st., Kazan, 420015, Russia \\ ${ }^{2}$ Kazan Federal University, Institute of Management, Economics and Finance, Kazan, 420008, Russia \\ ${ }^{3}$ Kazan State Academy of Veterinary Medicine, 35 Siberian highway st., Kazan, 420029, Russia \\ Correspondence: Abramkin S. A., Kazan State Agrarian University, 65 K. Marx st., Kazan, 420015, Russia.
}

Received: March 10, 2015 Accepted: March 31, 2015 Online Published: April 30, 2015

doi:10.5539/ass.v11n11p259 URL: http://dx.doi.org/10.5539/ass.v11n11p259

\begin{abstract}
The development of economic processes in the contemporary peace requires symmetrical efforts for guaranteeing the stability of markets as a whole and financial markets in particular. The development of financial markets is located under the effect of the development of economic systems and vice versa. In this connection questions of the adequate evolution of financial supervision become very urgent. In the article problems and questions of the activity of mega-regulator in Russia in the context of the world experience of active financial policy and regulation of financial markets are illuminated. Are examined prospects, problems and marks of possible versions. The conceptual vision of nature of the development of the mega-regulation of financial markets as immanent institute in the social-economic system, is stated.
\end{abstract}

Keywords: Mega-regulator, Bank of Russia, regulation, financial markets, risks, economics

\section{Introduction}

As a result the developments of economic thought after financial crisis are placed most important questions with respect to the expediency of the economic concept of markets and behavior, which occurred for a period of the recent decades of the domination of politicians in control of financial system. In response to this some regulators begin to reexamine their understanding of the behavior of the subjects within the framework of financial markets. Nevertheless, the base concept of the dynamics of markets themselves remains almost constant. In order to regulate financial markets, we need the more complex and more realistic cognitive structures, by means of which is possible to analyze their dynamics and on basis of which is effective the realization of their regulation (Black, 2013). The model of financial policy is the important side of the activity of financial regulator. Contemporary studies show that different money interferences can have different qualitative actions on the activity of tuning economic systems, and the standard operations on the open market, carried out by central banks have the important multiplying consequences for the overestimation in the economic system, in particular, beneficially influencing level and distribution of wealth and creating in subjects stimuli for the labor and preserving them to the output to pension (Sterk \& Tenreyro, 2013). Effective banking system is the center section of the economy (Kapoor \& Goodhart, 2013). A question of approach to the formation of strategy of the formation of national banking system will in many respects determine the future of social and economic social development. Enumerated, and some other problems and questions in their interconnection we attempted to examine in our work.

\section{Main Body}

Evolution of the macro-medium of financial markets, their multifactor transparency (Johannesen \& Zucman, 2014), be reflected in an increase in the role of central banks as the mega-regulators. The central bank of Russia since September 2013 began to fulfill the functions of the mega-regulator of financial markets. The totality of the action of global factors and their multiplicated consequences, in particular, such as, amplitude market fluctuations, cyclic economic trends, variative political instability, strongly affect need for representation in the financial policy and regulation at the macroeconomic level of the system, built during the cognitive absorption of information for the effective heuristic simulation of the multifactorial effect on national financial markets and economic system as a whole. From those affirmed by Russia bank in November 2014 "basic directions of united 
state money and credit policy in 2015 and period 2016 and 2017" follows that the authorities of mega-regulator make it possible to combine the measures of money and credit policy with the measures in the region of bank regulation and regulation of financial market and more effectively to attain purposes. As the intermediate they come out targeting of inflation and the guarantee of stable functioning and development is bank GO of sector, financial market and pay system. By the final goal in the document is relied increase and retention at the high level of the welfare of citizens, what is the quintessence of state economic policy. At the same time, in the document indicated it is provided, that $\mathrm{v}$ from the efficient cases, when their parallel reaching is hindered, Russia bank acts in the dependence on the situation on the basis of the analysis of risks and estimation of the for long urgent consequences of their realization.

This reservation is based on understanding of existence of antagonistic beginning in nature of economic processes, and it means also in the directions, the tools and the measures for realizing of polyfunctional policy of central bank. At the same time, it is widely-known that the dialectics, as the science about the development, is based on the action of the law of the unity and conflict of opposites. In this aspect, the concentration of system-forming functions in united mega-regulator, contributes to the most effective complex permission of this problems - the system convergence of financial policy and regulation on the financial markets to the stimulation of the economy on the dialectical methodological basis. In particular, is created favorable medium for introducing the mechanisms, which make it possible to explain the empirical answers of basic macroeconomic variables in the interventions of money and credit policy (Kirshin, Maleev, \& Pachkova, 2014).

The consolidation of the functions of financial macro-regulator in central bank of Russia positively will be said in the dissipation of financial system risks. The consolidation of the sectors of financial market in the united methodological field assists to the harmonization of prudential standards and will increase the quality of regulating functions central bank.

However, mega-regulator will be able to solve more complex problems - cross-sectored regulation and prudential supervision of the systemically significant subjects of market. In our opinion, the isolation of two levels of regulation medium will be methodological substantiated. At the base systemically important level into the integral macro-basis of supervision requirements it is necessary to place the united standardized methodological platform. On this basis, in the detailed, adaptive aspect of the diffusion of supervision requirements into the organizational- information massifs of administrative calculation, protocols and the procedures of business-processes, corporate document turnover, must it will be built the effective construction, which includes the self-controlled organizations of the participants in the market, who can take upon themselves "last mile" for the completing realizations function of system integration, and also control of the observance of some more utilitarian requirements, norms. Two-bin system (Figure 1.) will allow mega-regulator to be focused during the combined regulation in the section of financial groups and cross-sectored, where the level of uncertainty grows, and risks become more complexly and are less forecast, and to also build indicative supervision of the systemically significant companies on the financial markets.

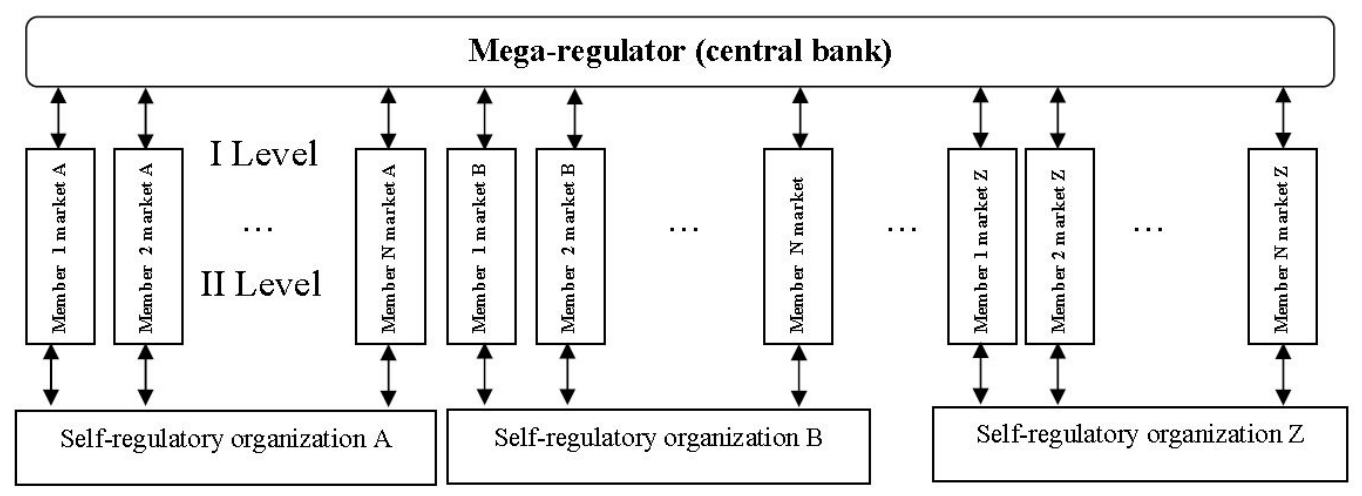

Figure 1. The two-bin system of the regulation of the financial markets

At the same time, having it should be noted that included in the focus of attention controlling, insurance and investment companies, non-governmental Pension funds, micro-financial organizations, in the outlying region are left two more sufficient relevant segment of the financial markets, which fall out for the perimeter of the authorities of mega-regulator - leasing and factoring. Palliative approach can decrease macroeconomic effect. Certainly, leasing and factoring companies - these are immanent participants in the financial market, their risks 
diffuse with the risks of remaining players and, as a minimum, this is reserve for expanding the perimeter of mega-regulation. It is definitely logical it will be logical to supplement by them in the near future the system of prudential measures and requirements. It is completely possible that the value of the fastest creation of the experience of the precedent of global regulation hung somewhere else loss because of the incompleteness of the obtained system, in view of the scarcity of apparatus resources. In our view, it is important to use cognitive approach for understanding "of incompleteness" in questions of construction and realization of strategies. Mathematician Gödel formulated the theorem about the incompleteness - any final system of axioms either is incomplete or it is contradictory. Let us suppose you have a plan, and you assume that they provided everything need, resources, feedback, etc However, Gödel it asserts: in the system one disregarded event, which completely destroys it will always be located. Consequently, after the framework of axiomatic (isolated logic circuits) it is possible and it is necessary to act on the basis the cognitive analysis of empirical experience. Extrapolating that state above into the sphere of supervision of the financial markets, let us say that it would be error represent the regulation in the form of the finite set of rules and algorithms. Possibly, to more correct it would be propose the development in the direction of creation adaptive, free from excess tabouisation, justifying, delicate control system with the internal mechanisms of self-adjusting (according to the operating principle of the economic built-in shock absorbers).

By the example to flexibilities and careful pedaling in questions of regulation is transfer the central bank of that planned earlier on January 1, 2015. the introduction of the index of the short term liquidity (it relates to the system "Basel III") on half a year - until July 1, 2015. As is known, at the basis of the concept of riskmanagement the priority of the purpose of stabilization to administrative system lies. From this example one can see well, that the principle "doing harm" has decisive importance in realizing of supervision policy. Postponement is connected with the politicized inspiration of the external sources of the allocation of that led to the problems in obtaining by the banks of access to the long-term resources. It is possible to say that central bank of Russia it reexamined the map of risks, after changing the period of the introduction of requirement, which assists to banking system more qualitatively to be prepared for the performance of norm. It goes without saying, besides those designated it is above sanctions, entire totality of the factors of macroeconomic situation in the country was considered with decision making. Let us note also that multivariate is placed in the basic directions of money and credit policy central bank of Russia.

Today for Russia and countries of the European Union are characteristic an increase in the sovereign risk, which leads to the significant capital flight, external adjustments and compressions of import (Bahaj, 2014). In this connection the activity of regulator cannot go around the outside markets by attention. Large macroeconomic potential is placed in the optimization of control of the capital movement - in this the source of an increase in welfare and disclosure of the possibilities of regulating as the tool the financial policy for the softening of the irrational use of resources, correction of the structural unbalances of economy and rise in productivity (Paterson, 2014).

Let us affect some topical aspects of endogenous risks. Are today on the loan financial market of Russia in earnest concerned by the creation of the universal systems of restructuring debts with the attraction of the organizational possibilities of the self-controlled organizations, in particular, the associations of Russian banks. The discussion deals with the creation of the global base of data and coordination of the activity of credit establishments in the work with the problematic debts. Are heard calls to the creation of the special product of restructuring as "packed product", similar to depozitnomu and credit. The work on the methodological, technological and organizational guarantee of this direction is conducted.

The changes and the innovations, which are concerned the procedures of restructuring, introduce themselves in the system of bank business- processes. I.e., at the level the business of planning is introduced the new form of activity, resources are separated, key indicators are developed. In our view, similar direction of bank thought not completely efficiently in the strategic aspect as encouraging at the organizational-technological level of error in control of strategic risks. To the it turns out that existing administrative paradigm can be embedded high risk and low quality of active memberships, and the efforts of managers are reoriented to the work with the consequences of this financial policy. Is necessary system aid at the level of regulator in all aspects from the methodological aid in understanding of logic and feedback of the formation of business- processes, to administrative-regulation tabouisation through the limiting barriers. To the existing approaches of the solution of the problem of zakreditovannosti - with the aid of the law and the law court or the market and regulation (Paterson, 2014), in our opinion, should be added the adaptive combining of tools and methods.

Speaking about the system risks under the changed conditions - consequence of the crises, excessive derivatization of fund markets, poor debts, etc, financial markets themselves need the evolution of methods and 
approaches to regulation (Benigno \& Fornaro, 2014). In this context, in our opinion, it would be possible to formulate several questions. Is possible whether the creation of conditions for the anticipating regulation, or there is a methodological barrier of the permanent movement after the tendency, forced to react in the regime post factum? The anticipating action will not dispute with the legislation about the protection of competition, anti-monopolistic and other? Is there no risk of unconscious manipulation or unbalancing of markets?

Without carrying out in-depth research of the within the framework this article, let us express the opinion that the positive influence of mega-regulation will depend on the desire of regulator to be concentrated on the control of risks in the financial system, and the creation of the system of motivations and stimuli, while not during the simple observance of norms, instructions and other tools of the realization of policy, or on the hard constraint of banks and non banking financial institutes in the possibility by different manipulations "on the verge" to avoid fulfilling the requirements of normative reports.

The value of analysis is reached by its permanence. Russia bank in 2015 plans to develop the project of basic trends in development and guarantee of stability of the functioning of financial market.

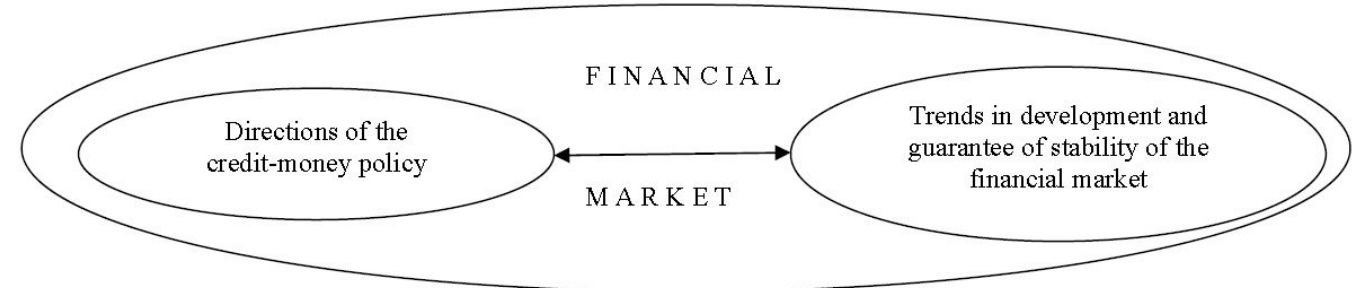

Figure 2. Directions of the policy of mega-regulator on the financial market For Russia

The appearance of the document indicated will make it possible to more qualitatively estimate the strategic and tactical approaches of mega-regulator. Relying on it, many of the presented in this article problems and the questions can obtain material for the search for the solutions and answers. At the same time, the carried out analysis, without pretending to the comprehensive completeness, makes it possible to extract basic proposals and expectations. In our opinion, the factor of the centralization of regulation and supervision on the financial markets is capable to serve obtaining synergetic effect from the consolidation of apparatus, organizationalstructural reformation, acquisition of the new stimulating, justifying functions and development of those existing.

The conformism at the strategic level, capable of leading to the smoothing of the influence of antagonistic sets of instruments is made itself possible, attaining through the through permanent information monitoring of the convergence of financial policy and regulating measures in an increase in the effectiveness of economic system. Is possible, is necessary to think about the flexible hybrid method, which is been located out of the rigid definitsionny field and absorbing with the multivariate behavior of economic systems the applied semantically polyfunctional the simulation of regulating activity. Contemporary conditions require creative, cognitive approaches (Black, 2012) with the possible combining of the previously considered antagonistic, in the opinion orthodoxes from the economic theory, the approaches.

Thus, at first glance paradoxical antagonistic of the postulated purposes of fight with the inflation and stimulations of increase is solved by Russia bank by extrapolation on the chain of the multiplied levers. It is understandable that this policy does not allow for the possibility of obtaining the immediate result, its effectiveness can be not evaluated by populists. But, in our opinion, this testifies about ripening of the national economy, qualitative development of its institutes and infrastructure, its ability to solve serious problems not administrative- command methods, but with the aid of the intelligent long-term policy.

Table 1. Exemplary conceptual diagram of strategizing of the mega-regulator

\begin{tabular}{|c|c|c|c|}
\hline Mission & Basic purposes & Basic functions & Modus of the action \\
\hline $\begin{array}{l}\text { Increase in } \\
\text { the welfare } \\
\text { of the } \\
\text { citizens }\end{array}$ & $\begin{array}{l}\text { Targetirovanie of inflation, } \\
\text { guarantee of stable functioning and } \\
\text { development is bank GO of sector, } \\
\text { financial market and pay system }\end{array}$ & $\begin{array}{l}\text { Supervision, } \\
\text { regulation, the } \\
\text { money and credit } \\
\text { policy }\end{array}$ & $\begin{array}{l}\text { System cognitive convergence of } \\
\text { the polyfunctional set of } \\
\text { instruments of mega-regulation to } \\
\text { the stimulation of the economy }\end{array}$ \\
\hline
\end{tabular}




\section{Conclusion}

Overcoming the consequences of the financial crisis, opposition to today's calls, the dissipation of the appearing complex multifactorial economic and financial risks in the future, requires the qualitatively new solutions in the system comprehension of the mechanisms of functioning and evolution of financial markets. The problem of this scale can be effective solved by creation on the base of the regulator of the universal integral system of the total dynamic monitoring of economic and financial systems. The assembled information, penetrating the cognitive analysis, must contribute to the generation of the qualitative pulses of the cross-sectored regulation within the framework of the global balanced financial policy with the subsequent convergence into the stimuli of economic increase. In the promising version it is good to recreate the model of regulation as the immanent part of the social-economic and financial medium with the synergetic potential of adaptive self-development.

Methodological postulate about the isolation of central component with respect to financial markets concerns banking system. Formation on the united organizational- structural base of the possibilities of the sequential conducting of the harmonized financial policy on scales of the economy will make it possible to extrapolate the embedded into the bank nucleus of financial system regulational standards and principles on entire financial market.

\section{References}

Bahaj, S. A. (2014). Systemic sovereign risk: macroeconomic implications in the euro area. CFM discussion paper series, CFM-DP2014-6. Centre For Macroeconomics , London, UK.

Benigno, G., \& Fornaro, L. (2014). The financial resource curse. Scandinavian Journal of Economics, 116(1), $58-86$.

Black, J. (2012). Restructuring global and EU financial regulation: character, capacities and learning. In E. Wymeersch, K. J. Hopt, \& G. Ferrarini (Eds.), Financial Regulation and Supervision: a Post-Crisis Analysis. Oxford University Press, Oxford, UK.

Black, J. (2013). Reconceiving financial markets: from the economic to the social. Journal of Corporate Law Studies, 13(2), 401-442. http://dx.doi.org/10.5235/14735970.13.2.401

Johannesen, N., \& Zucman, G. (2014). The end of bank secrecy? An evaluation of the G20 tax haven crackdown. American Economic Journal: Economic Policy, 6(1), 65-91. http://dx.doi.org/10.1257/pol.6.1.65

Kapoor, S., \& Goodhart, C. (2013). Plans for a banking union may not be enough to tackle the eurozone's economic crisis. 2013 European Politics and Policy at LSE (04 Feb 2013) Blog Entry.

Kirshin, I. A., Maleev, M. V., \& Pachkova, O. V. (2014). Assessment of Impact of Domestic and External Demand Factors on Economic Growth in Russia on the Basis of Model of Multiple Regression Analysis. Procedia Economic and finance, 14, 320-325. http://dx.doi.org/10.1016/S2212-5671(14)00719-9

Larionova, N. I., \& Varlamova, Yu. A. (2013). The Trends of Household Economic Behavior in International Comparison. Procedia Economic and finance, 5, 737-746. http://dx.doi.org/10.1016/S2212-5671(13) 00086-5

Paterson, S. (2014). Bargaining in financial restructuring: market norms, legal rights and regulatory standards. Journal of Corporate Law Studies, 14(2), 333-365. http://dx.doi.org/10.5235/14735970.14.2.333

Safiullin, L. N., Novenkova, A. Z., \& Safiullin, N. Z. (2014). Utility and Demand in the New Economy. Procedia Economic and finance, 14, 559-564. http://dx.doi.org/10.1016/S2212-5671(14)00756-4

Sterk, V., \& Tenreyro, S. (2013). The transmission of monetary policy operations through redistributions and durable purchases. 2013 CFM discussion paper series, CFM-DP2013-5. Centre For Macroeconomics, London, UK.

\section{Copyrights}

Copyright for this article is retained by the author(s), with first publication rights granted to the journal.

This is an open-access article distributed under the terms and conditions of the Creative Commons Attribution license (http://creativecommons.org/licenses/by/3.0/). 